\title{
Impactos de Políticas de Desoneração do Setor Produtivo: Uma Avaliação a Partir de um Modelo de Gerações Superpostas ${ }^{\dagger}$
}

\author{
- Marco Antônio Freitas de Hollanda Cavalcanti* \\ - Napoleão Luiz Costa da Silva**
}

\begin{abstract}
Resumo
O objetivo deste trabalho é contribuir para o debate sobre a forma ideal de desoneração do setor produtivo, através da simulação de diferentes medidas de reforma tributária no País, a partir de um modelo de equilíbrio geral com gerações superpostas, calibrado para o Brasil. Busca-se, em particular, comparar medidas de desoneração do fator trabalho e medidas de desoneração do fator capital, ambas compensadas por aumentos na tributação do consumo, no que tange a seus impactos esperados sobre o PIB, acumulação de capital e nível de bem-estar no País. De acordo com os resultados obtidos, a desoneração do fator capital pode levar a aumentos substanciais de capital e produto relativamente à desoneração do fator trabalho. Ambas as políticas devem gerar perdas de bem-estar para as gerações mais velhas existentes no momento da reforma tributária e ganhos de bem-estar para as gerações futuras, mas os efeitos sobre as gerações intermediárias podem ser bastante distintos em cada caso.
\end{abstract}

\section{Palavras-Chave}

política fiscal, desoneração tributária, gerações superpostas

\begin{abstract}
This paper aims to contribute to the debate on the best way to reduce the tax burden on the production sector in Brazil, by simulating an overlapping generations model calibrated to the country's economy. Our focus is on the comparison of the macroeconomic and welfare impacts brought about by policies that reduce the tax burden on labour and policies based on the reduction of the tax burden on capital. According to our results, reducing the tax burden on capital may lead to substantial gains in terms of capital accumulation and GDP relative to reducing the burden on labour. Both types of policies must generate welfare losses to elderly generations alive when the reform takes place and welfare gains to future generations, but the effects on intermediate generations may differ substantially under each policy.
\end{abstract}

\section{Keywords}

fiscal policy, tax reform, overlapping generations

\section{JEL Classification}

$\mathrm{E} 60, \mathrm{H} 2 \mathrm{O}$

\footnotetext{
- Os autores agradecem os comentários dos participantes de seminário realizado no IPEA, onde uma versão anterior do trabalho foi apresentada, bem como as sugestões de um parecerista anônimo.

* Instituto de Pesquisa Econômica Aplicada (IPEA). E-mail: marco.cavalcanti@ipea.gov.br.

** Instituto de Pesquisa Econômica Aplicada (IPEA). E-mail: napoleao.silva@ipea.gov.br.

Endereço para contato: Av. Presidente Antônio Carlos 51 - Rio de Janeiro - RJ. CEP: 20020-010.

(Recebido em maio de 2009. Aceito para publicação em abril de 2010).
} 


\section{Introdução}

É quase consensual entre os economistas brasileiros que o sistema tributário nacional apresenta várias distorções que prejudicam o desempenho econômico do País. Entretanto, não parece haver concordância com relação às medidas prioritárias a serem adotadas visando reformar o sistema. Uma das questões em aberto diz respeito à desoneração do setor produtivo nacional; a maioria das propostas recentes de reforma tributária inclui algum subconjunto de medidas visando tal objetivo, mas a natureza dessas medidas varia substancialmente entre as diversas propostas. Em particular, é possível classificar as propostas de desoneração do setor produtivo em duas categorias: medidas que buscam basicamente reduzir a tributação sobre o fator trabalho, como a substituição de parte da contribuição previdenciária por um imposto sobre o valor adicionado (IVA) do tipo consumo, e medidas que visam desonerar principalmente o fator capital, como a redução na tributação do investimento produtivo e a redução na tributação indireta sobre bens de capital (AFONSO; VARSANO, 2004; SILVA et al., 2004; EC 42 de 2003 e SPE-MF, 2007).

A falta de consenso acerca da forma ideal de desoneração do setor produtivo reflete, em parte, a incerteza relativa aos impactos macroeconômicos e de bem-estar que cada tipo de medida acarretaria. O objetivo deste trabalho é contribuir para o melhor entendimento dessa questão, através da simulação de diferentes medidas de reforma tributária no País a partir de um modelo de equilíbrio geral com gerações superpostas (OLG, na sigla em inglês), na linha de Auerbach e Kotlikoff (1987). Em particular, busca-se comparar medidas de desoneração do fator trabalho e medidas de desoneração do fator capital, ambas compensadas por aumentos na tributação do consumo, no que tange a seus impactos esperados sobre o PIB, acumulação de capital e nível de bem-estar no País.

Cabe destacar que, no contexto dos modelos OLG desenvolvidos a partir do trabalho pioneiro de Auerbach e Kotlikoff (1987), algumas das consequências qualitativas de se tributar mais fortemente determinada base tributária são relativamente previsíveis. Em particular, é razoável esperar que, no longo prazo, a economia acumule mais capital e atinja níveis mais elevados de produto em um sistema tributário que onere mais fortemente o consumo relativamente às atividades produtivas, ou o fator trabalho relativamente ao fator capital. Além disso, quanto maior a tributação do consumo relativamente à produção, maiores devem ser os ganhos de bem-estar das gerações mais novas, que podem decidir sobre quanto trabalhar, consumir e poupar, em comparação com as gerações mais velhas, que apenas consomem o estoque de capital acumulado no passado. Entretanto, ainda que alguns dos resultados de mudanças tributárias sejam previsíveis em termos qualitativos, as magnitudes desses efeitos podem variar significativamente em função das características específicas 
da economia analisada. Além disso, outros resultados de interesse não são necessariamente óbvios, nem mesmo em termos qualitativos; por exemplo, os impactos de bem-estar de uma reforma tributária que envolva a redução da tributação sobre o capital, compensada pelo aumento da tributação do consumo, são ambíguos, e dependem de forma crucial das características da economia. Nesse sentido, a realização de exercícios de simulação de diferentes regimes tributários a partir de um modelo calibrado para a economia brasileira - incorporando, em particular, importantes aspectos da demografia do País -, pode fornecer importantes insights sobre alguns dos efeitos diferenciados que estratégias alternativas de reforma tributária poderiam acarretar para o País.

Vale destacar que existe uma extensa literatura recente sobre os possíveis impactos de reformas tributárias e previdenciárias no Brasil: Barreto e Oliveira $(1995,2001)$, Barreto (1997), Lannes Jr. (1999), Lannes Jr. e Oliveira (1998), Ellery Junior e Bugarin (2003), Ferreira (2004) e Vigna (2006) avaliaram os impactos de reformas no sistema de previdência social; Ferreira e Araújo (1999), Lledo (2005) e Fochezatto e Salami (2009) avaliaram os impactos de propostas de reformas no sistema tributário nacional; e Menezes e Barreto (1999) e Teles e Andrade (2006) simularam os efeitos conjuntos de reformas tributárias e previdenciárias. Essa literatura, porém, não se preocupou em comparar detalhadamente os possíveis impactos macroeconômicos e de bem-estar de diferentes políticas de desoneração do setor produtivo. O presente trabalho contribui, assim, para preencher essa lacuna. Além disso, o trabalho inova em relação aos estudos anteriores para o Brasil no que se refere à especificação do modelo de simulação, que incorpora custos de ajustamento do capital e incerteza quanto ao tempo de vida de cada geração, e à calibragem do mesmo, baseada nas novas Contas Nacionais divulgadas em 2007 e na tábua de mortalidade por idade do IBGE, que permite captar aspectos da estrutura demográfica do País, ignorados em trabalhos anteriores.

O trabalho está estruturado em cinco seções, além desta Introdução: a seção 2 discute os mecanismos através dos quais diferentes medidas de reforma tributária poderiam acarretar, no contexto de um modelo OLG padrão, impactos sobre as variáveis macroeconômicas e níveis de bem-estar da população; a seção 3 descreve o modelo teórico utilizado na análise; a seção 4 apresenta os parâmetros utilizados e os procedimentos de calibração do modelo; a seção 5 discute os resultados dos exercícios de simulação, e a seção 6 tece os comentários finais. 


\section{Mudanças Tributárias em Modelos OLG: Breve Revisão da Teoria}

Nas simulações a serem discutidas a seguir, serão analisados dois exercícios básicos de desoneração do setor produtivo: no primeiro, a alíquota do tributo sobre a renda do trabalho será reduzida, sendo a perda de arrecadação resultante compensada pelo aumento na tributação sobre o consumo das famílias; no segundo exercício, haverá redução da alíquota do tributo sobre o lucro das empresas, também compensada pelo aumento na tributação do consumo. Trata-se, portanto, de exercícios de mudança compensada de base tributária: em ambos os casos, reduz-se a tributação da produção relativamente ao consumo, sendo que, no primeiro caso, reduz-se também a tributação do fator trabalho relativamente ao capital, enquanto que, no segundo caso, ocorre o inverso.

No contexto dos modelos OLG desenvolvidos a partir do trabalho de Auerbach e Kotlikoff (1987), algumas das consequências qualitativas de se tributar mais fortemente determinada base tributária são razoavelmente conhecidas. Em particular, tais modelos preveem que: ${ }^{1}$

a) A desoneração da produção relativamente ao consumo deve levar, no longo prazo, à maior acumulação de capital e a níveis mais elevados de produto, além de gerar ganhos de bem-estar para as gerações mais novas, relativamente às mais velhas. A razão básica para tais efeitos está associada ao fato de que a mudança tributária em questão promove uma redistribuição dos recursos da economia em favor das gerações mais novas, cujos rendimentos dependem mais fortemente das atividades produtivas. Isso explica diretamente os ganhos relativos de bem-estar dessas gerações. Além disso, dada a maior propensão a consumir das gerações mais velhas, que reflete seu tempo de vida restante mais curto, ${ }^{2}$ essa redistribuição de recursos tem como consequência a redução do consumo agregado e a elevação da oferta de trabalho e da poupança agregada - e, portanto, o aumento do estoque de capital e do produto da economia.

b) A desoneração do fator capital relativamente ao fator trabalho também deve levar, no longo prazo, a maiores níveis de capital e produto na economia, devido fundamentalmente ao efeito substituição associado ao barateamento relativo do capital. Sob tal política, ocorre uma redistribuição de recursos favorável, principalmente, às gerações intermediárias existentes na data de implementação da política, que detêm maiores estoques de capital, e possivelmente também às gerações que deverão nascer no futuro e poderão se beneficiar do maior estoque de capital na economia.

1 Ver, em especial, Auerbach e Kotlikoff (1987, cap.5).

2 E também o fato de que, no modelo básico, não há heranças. 
Cabe notar que as magnitudes dos efeitos acima dependem crucialmente de certas características da economia analisada, em particular da estrutura demográfica do país e do tamanho relativo do governo. A importância da estrutura demográfica está associada ao fato de que, no caso de mudanças tributárias compensadas, os "efeitos renda" da política decorrem da redistribuição dos recursos entre as diversas gerações de indivíduos, e não de um efeito global para o setor privado; logo, a expectativa de vida de cada geração, que determina o peso que cada geração atribui ao consumo corrente vis-à-vis ao consumo futuro, e o tamanho relativo de cada geração, que estabelece seu peso na população total e no setor privado como um todo, são elementos cruciais na determinação do efeito líquido de medidas de reforma tributária. Por sua vez, a relevância do tamanho do governo na economia representado pela fração do PIB consumida pelo governo - decorre do fato de que o impacto da taxação distorciva na geração de ineficiência econômica aumenta de forma não linear com a magnitude das alíquotas tributárias; consequentemente, quanto maior o grau inicial de taxação, maiores devem ser os ganhos de eficiência (e, portanto, de produto) a serem auferidos na transição para sistemas baseados em impostos menos distorcivos - por exemplo, na passagem de um sistema baseado na taxação da produção para um sistema baseado na taxação do consumo.

\section{O Modelo}

O modelo de simulação utilizado é um modelo dinâmico de equilíbrio geral com gerações superpostas que inclui três setores: famílias, setor de produção e governo. Trata-se de uma extensão do modelo com custos de ajustamento do capital de Auerbach e Kotlikoff (1987), ao qual é adicionada incerteza quanto ao tempo de vida de cada família, conforme Jokisch e Kotlikoff (2007).

\subsection{Setor Famílias}

Em cada ponto no tempo, o setor famílias é composto por 55 gerações superpostas de adultos. Elas vivem no máximo 55 períodos (anos). A cada ano "nascem" famílias da primeira geração e morrem famílias de todas as outras gerações. A taxa de mortalidade de cada geração, de um ano para o ano seguinte, é definida pela probabilidade condicional de cada geração viver mais um ano. As preferências individuais são idênticas e as diferenças entre os indivíduos surgem em função das diferentes gerações a que pertencem. As famílias fazem decisões intertemporais sobre consumo e lazer e não recebem nem deixam heranças de forma voluntária. ${ }^{3}$

3 A riqueza deixada pelos que morreram é distribuída igualmente entre todas as famílias vivas em um dado período de tempo. 
As preferências de cada família são representadas por uma função utilidade separável e invariante no tempo, encadeada e com elasticidade constante de substituição (CES). A função de utilidade intertemporal é dada por:

$$
U=\frac{1}{1-\frac{1}{\gamma}} \sum_{t=1}^{55}(1+\delta)^{-(t-1)} p_{t} u_{t}^{\left(1-\frac{1}{\gamma}\right)}
$$

Onde $u_{t}$ é dado por:

$$
u_{t}=\left[c_{t}^{\left(1-\frac{1}{\rho}\right)}+\alpha l_{t}^{\left(1-\frac{1}{\rho}\right)}\right] \overline{\left(1-\frac{1}{\rho}\right)}
$$

$\mathrm{Na}$ equação (2), $c_{t}$ e $l_{t}$ correspondem ao consumo e ao lazer dos indivíduos com a idade $t$. O lazer é medido como uma fração do montante máximo de tempo que um indivíduo pode trabalhar em um dado ano. $\mathrm{O}$ parâmetro $\gamma$ corresponde à elasticidade de substituição intertemporal, $\rho$ representa a elasticidade de substituição intratemporal entre consumo e lazer, $\delta$ é a taxa de desconto, $\alpha$ representa o peso dado ao lazer na função utilidade e $p_{t}$ representa a probabilidade de uma família viver $t$ períodos. Cada família escolhe os caminhos do consumo e lazer visando maximizar sua função de utilidade intertemporal, sujeita à sua restrição orçamentária.

Em cada período, as famílias decidem quanto trabalhar e quanto consumir. Os rendimentos do trabalho e do capital, não utilizados para consumo, são poupados e adicionados ao estoque de ativos das famílias. A restrição orçamentária é definida pelo requerimento de que o valor presente do consumo ao longo da vida seja menor ou igual ao valor presente dos rendimentos ao longo da vida:

$$
\sum_{t=1}^{55} \prod_{m=1}^{t}\left[1+r_{m}\left(1-\tau_{y m}\right)\right]^{-1}\left[w_{t} e_{t}\left(h_{t}-l_{t}\right)\left(1-\tau_{l t}-\tau_{y t}-\tau_{s t}\right)-\left(1+\tau_{c t}\right) c_{t}+b_{t}\right]+P V B \geq 0
$$

onde $r_{t}$ é a taxa de juros no ano $t, w_{t}$ é a taxa de salário no ano $t$ e $e_{t}$ representa um fator de ajuste que permite que o rendimento varie com os diferentes níveis de habilidades das famílias de diferentes idades. A alíquota do tributo sobre a renda do trabalho é representada por $\tau_{l t}$, a alíquota do tributo sobre o consumo é dada por $\tau_{c t}$ e $\tau_{y t}$ representa a alíquota dos impostos sobre a renda geral, cuja base é uma combinação entre a renda do trabalho e a do capital, que não pode ser facilmente identificada; $\tau_{s t}$ representa a alíquota das contribuições para a seguridade social e 
PVB é o valor presente das transferências recebidas do sistema de seguridade social a título de aposentadorias. O sistema de seguridade é do tipo de repartição simples, ou seja, não capitalizado (PAYG), segundo o qual as aposentadorias pagas em cada período são financiadas pelos indivíduos que trabalham naqueles mesmos períodos. O termo $b_{t}$ representa a herança recebida das famílias que morreram no ano $t$, onde supomos que a riqueza deixada pelos que morreram no ano $t$ é distribuída igualmente entre todos os que permaneceram vivos no ano $t$. O termo $h_{t}$ representa a dotação total de trabalho de uma família da geração $t$. Este termo cresce a cada ano a uma taxa constante dada pela taxa de progresso técnico $\phi:^{4}$

$$
h_{t}=h_{t-1}(1+\phi)
$$

Além da restrição orçamentária, temos a restrição de que a oferta de trabalho do indivíduo, a cada período, não pode ser negativa:

$$
l_{t} \leq h_{t}, \forall t
$$

A maximização da função utilidade intertemporal (1), sujeita à restrição orçamentária (3) e à restrição sobre o trabalho (5), fornece as condições de primeira ordem para o consumo e o lazer:

$(1+\delta)^{-(t-1)} p_{t}\left[c_{t}^{1-\frac{1}{\rho}}+\alpha l_{t}^{1-\frac{1}{\rho}}\right]^{\frac{1}{\rho}-\frac{1}{\gamma}}{ }^{\frac{1}{\rho}} c_{t}^{-\frac{1}{\rho}}=\lambda \prod_{m=1}^{t}\left[1+r_{m}\left(1-\tau_{y m}\right)\right]^{-1}\left(1+\tau_{c t}\right), \quad t=1,2, \ldots, 55$

$(1+\delta)^{-(t-1)} p_{t}\left[c_{t}^{1-\frac{1}{\rho}}+\alpha l_{t}^{1-\frac{1}{\rho}}\right]^{\frac{1}{\rho}-\frac{1}{\gamma}} \frac{1-\frac{1}{\rho}}{\rho} \alpha l_{t}^{-\frac{1}{\rho}}=\lambda \prod_{m=1}^{t}\left[1+r_{m}\left(1-\tau_{y m}\right)\right]^{-1}\left[w_{t} e_{t}\left(1-\tau_{l t}-\tau_{y t}-\tau_{s t}\right)+\mu_{t}\right]$

$t=1,2, \ldots, 55$

onde $\lambda$ é o preço sombra (multiplicador de Lagrange) da restrição orçamentária intertemporal e representa o valor presente em termos de utilidade de uma unidade adicional de renda. $\mathrm{Na}$ equação (7), $\mu_{t}$ representa o salário sombra no ano $t$. Ele é igual a zero, se o indivíduo decide ofertar um montante positivo de trabalho, e é diferente de zero, se o indivíduo decide não trabalhar no ano $t$. Seu montante é

4 Esta forma de inserir progresso técnico no modelo significa que uma mesma geração fica mais eficiente a cada ano. 
definido pela diferença entre o salário ao qual o indivíduo ofertaria um montante positivo de trabalho e o salário efetivo $\left(w_{t} e_{t}\right)$.

Dividindo (6) por (7) e rearranjando os termos obtemos:

$$
l_{t}=c_{t}\left(\frac{w_{t} e_{t}\left(1-\tau_{l t}-\tau_{y t}-\tau_{s t}\right)+\mu_{t}}{\alpha\left(1+\tau_{c t}\right)}\right)^{-\rho}
$$

Esta equação fornece uma relação entre o consumo no período $t$ e o lazer no mesmo período. Substituindo (8) em (6) obtemos:

$(1+\delta)^{-(t-1)} p_{t} c_{t}^{-\frac{1}{\gamma}}\left(1+\alpha^{\rho} w_{t}^{*(1-\rho)}\right)^{\frac{\frac{1}{\rho} \frac{1}{\gamma}}{1-\frac{1}{\rho}}}=\lambda \prod_{m=1}^{t}\left[1+r_{m}\left(1-\tau_{y m}\right)\right]^{-1}\left(1+\tau_{c t}\right), t=1,2, \ldots, 55$

onde:

$$
w_{t}^{*}=\frac{w_{t} e_{t}\left(1-\tau_{l t}-\tau_{y t}-\tau_{s t}\right)+\mu_{t}}{\left(1+\tau_{c t}\right)}
$$

Dividindo a equação (9), para o período $t$, pela equação (9), para o período $t$-1, e rearranjando os termos, obtemos a equação de transição para o consumo do indivíduo:

$$
c_{t}=\left[\frac{1+r_{t}\left(1-\tau_{y t}\right)}{(1+\delta)} \frac{p_{t}}{p_{t-1}}\right]^{\gamma}\left[\frac{1+\tau_{c t-1}}{1+\tau_{c t}}\right]^{\gamma}\left(\frac{1+\alpha^{\rho} w_{t-1}^{*(-\rho)}}{1+\alpha^{\rho} w_{t}^{*(1-\rho)}}\right)^{\frac{\rho-\gamma}{\rho-1}} c_{t-1}, t=2,3, \ldots, 55
$$

onde:

$$
w_{t}^{*}=\frac{w_{t} e_{t}\left(1-\tau_{l t}-\tau_{y t}-\tau_{s t}\right)+\mu_{t}}{\left(1+\tau_{c t}\right)}
$$

Note que a relação $p_{t} / p_{t-1}$ representa a probabilidade condicional de uma família da geração $t$-l viver mais um ano. Substituindo (8) em (10) obtemos a equação de transição para o lazer do indivíduo: 


$$
l_{t}=\left[\frac{1+r_{t}\left(1-\tau_{y t}\right)}{(1+\delta)} \frac{p_{t}}{p_{t-1}}\right]^{\gamma}\left[\frac{1+\tau_{c t-1}}{1+\tau_{c t}}\right]^{\gamma}\left(\frac{1+\alpha^{\rho} w_{t-1}^{*(1-\rho)}}{1+\alpha^{\rho} w_{t}^{*(1-\rho)}}\right)^{\frac{\rho-\gamma}{\rho-1}}\left(\frac{w_{t-1}^{*}}{w_{t}^{*}}\right)^{\rho} l_{t-1}, t=2,3, \ldots, 55
$$

\subsection{Setor de Produção}

A economia possui um único setor de produção que se comporta competitivamente. A função de produção utiliza capital e trabalho para obter o produto agregado por meio de uma tecnologia com retornos constantes de escala. O capital é homogêneo enquanto o trabalho difere somente em seu grau de eficiência. Neste caso, todas as formas de trabalho são substitutos perfeitos, porém, indivíduos de diferentes idades ofertam diferentes montantes do mesmo insumo trabalho em um dado ano. Esta diferença é representada pelo termo $e_{t}{ }^{5} \mathrm{O}$ estoque de capital apresenta custos de ajustamento convexos, o que implica que, quanto maior a taxa de investimento, maior será o custo de ajustamento. ${ }^{6}$ A função de produção possui o formato padrão Cobb-Douglas e a renda é dada por:

$$
Y_{t}=A K_{t}^{\theta} L_{t}^{1-\theta}-0,5 \psi \frac{I_{t}^{2}}{K_{t}}
$$

onde $Y_{t}$ é o produto agregado líquido do custo de ajustamento, $K_{t}$ é o capital agregado e $L_{t}$ é o trabalho agregado; $\theta$ é a participação do capital na produção e $A$ é uma constante. $\mathrm{O}$ segundo termo na equação representa o custo de ajustamento do capital, onde $\psi$ é um parâmetro e $I_{t}$ é o investimento no período $t$. Além disso, o capital pertence aos indivíduos e é ofertado a cada período para as firmas, junto com o trabalho. Os lucros do setor produtivo são tributados segundo a seguinte regra:

$$
T_{t}^{E M P}=\tau_{e t}\left(Y_{t}-w_{t} L_{t}-\beta_{t} I_{t}\right)
$$

onde $\mathrm{T}^{\mathrm{EMP}}$ é o imposto sobre as empresas, $\tau_{\mathrm{et}}$ é a alíquota deste imposto e $\beta_{\mathrm{t}}$ representa o porcentual do investimento que é dedutível do imposto. Neste contexto, as condições de equilíbrio são dadas por:

$$
w_{t}=(1-\theta) A\left(\frac{K_{t}}{L_{t}}\right)^{\theta}
$$

5 Note que o termo $e_{t}$ varia para cada geração $t$. Para uma mesma geração ele é fixo ao longo do tempo. O termo que varia ao longo do tempo é $h_{t}$.

6 A introdução de custos de ajustamento do capital faz o investimento se ajustar de forma mais suave no modelo. Este ajustamento mais suave está de acordo com o comportamento do investimento observado nas economias reais. 


$$
\begin{aligned}
& q_{t}=1-\beta_{t} \tau_{e t}+\left(1-\tau_{e t}\right) \psi \frac{I_{t}}{K_{t}} \\
& r_{t} q_{t}=\left(1-\tau_{e t}\right)\left(\theta A\left(\frac{K_{t}}{L_{t}}\right)^{\theta-1}+0,5 \psi\left(\frac{I_{t}}{K_{t}}\right)^{2}\right)+q_{t+1}-q_{t}
\end{aligned}
$$

onde $q_{t}$ é o valor de uma unidade do capital existente. A equação (14) representa a igualdade entre salário real e produto marginal do trabalho. A equação (15) representa uma condição de arbitragem entre o preço de uma unidade do capital existente $\left(q_{t}\right)$ e o preço de reposição de uma unidade nova de capital (segundo membro da equação). Este é definido pela unidade menos as deduções permitidas pela depreciação $\left(\beta_{t} \tau_{e t}\right)$ mais o custo de ajustamento marginal que é plenamente dedutível do imposto. A equação (16) representa a condição de arbitragem, onde o retorno de se investir o montante $q_{t}$ na dívida do governo é igual ao retorno de uma unidade adicional de capital, que é dado pelo produto marginal do capital líquido de impostos (primeiro termo do segundo membro da equação) mais o ganho de capital $\left(\mathrm{q}_{t+1}-q_{t}\right)$.

\subsection{O Setor Governo}

O governo arrecada impostos para financiar seus gastos em bens e serviços. O modelo não considera efeitos indiretos dos gastos sobre as famílias e supõe, por simplicidade, que a taxa de crescimento do consumo do governo seja igual à taxa de crescimento do PIB. Além disso, existe um sistema de seguridade social separado e independente do restante do governo, que arrecada impostos sobre a folha de salários e realiza pagamento de benefícios. O resultado anual do sistema de seguridade é transferido para o restante do governo; se o sistema tem um déficit no ano, este é financiado pelo restante do governo; no caso de um superávit, o mesmo é apropriado pelo restante do governo. A variação do endividamento do governo total (incluindo a seguridade) é dada por:

$$
D_{t+1}-D_{t}=G_{t}+S_{t}+r_{t}\left(1-\tau_{y t}\right) D_{t}-T_{t}
$$

onde:

$$
T_{t}=\left(\tau_{l t}+\tau_{y t}\right) w_{t} L_{t}+\tau_{c t} C_{t}+\tau_{y t} r_{t} K_{t}+T_{t}^{E M P}+T_{t}^{S E G}-\text { transf } f_{t}
$$


Nas equações acima, $D_{t}$ é a dívida do governo no ano $t, G_{t}$ é o gasto do governo em bens e serviços, $S_{t}$ são os pagamentos do sistema de seguridade, $r_{t} D_{t}$ corresponde aos juros sobre a dívida, $T_{t}$ é a arrecadação líquida de tributos, $C_{t}$ é o consumo agregado, $T^{S E G}$ representa as contribuições para o sistema de seguridade e $\operatorname{trans}_{t}$ representa as transferências do governo (exclusive transferências de juros e do sistema de seguridade). A substituição sucessiva em (17) para $t$ variando de 0 até $N$ fornece:

$$
\begin{aligned}
& \sum_{t=0}^{N}\left[\prod_{m=0}^{t}\left[1+r_{m}\left(1-\tau_{y m}\right)\right]^{-1}\right] T_{t}=\sum_{t=0}^{N}\left[\prod_{m=0}^{t}\left[1+r_{m}\left(1-\tau_{y m}\right)\right]^{-1}\right]\left(G_{t}+S_{t}\right)+D_{0}- \\
& -\left(\prod_{t=0}^{N}\left[1+r_{t}\left(1-\tau_{y t}\right)\right]^{-1}\right) D_{N}
\end{aligned}
$$

Supomos que a taxa de crescimento da dívida seja menor do que a taxa de juros para $N$ "suficientemente grande", ou seja, que a dívida não possa crescer a uma taxa igual ou superior à taxa de juros indefinidamente. Neste caso, o último termo da equação (19) tende a zero quando $N$ tende a infinito. A restrição orçamentária do governo em (19) se reduz ao requerimento de que o valor presente da arrecadação de tributos seja igual ao valor presente dos gastos do governo mais o valor inicial da dívida:

$$
\sum_{t=0}^{\infty}\left[\prod_{m=0}^{t}\left[1+r_{m}\left(1-\tau_{y m}\right)\right]^{-1}\right] T_{t}=\sum_{t=0}^{\infty}\left[\prod_{m=0}^{t}\left[1+r_{m}\left(1-\tau_{y m}\right)\right]^{-1}\right]\left(G_{t}+S_{t}\right)+D_{0}
$$

\subsubsection{O Sistema de Seguridade Social}

A seguridade social é modelada separadamente do restante do governo descrito acima. O sistema de seguridade é definido como um sistema de repartição simples, ou seja, não capitalizado (pay-as-you-go). Os benefícios da seguridade são recebidos a partir dos 46 anos de idade (em torno de 66 anos se considerarmos o tempo real) e continuam até a morte do indivíduo aos 55 anos (75 anos em tempo real). Os benefícios são relacionados a uma média dos rendimentos passados. No modelo, a média dos rendimentos ao longo dos primeiros 45 anos de vida é chamada de AIME. A taxa de reposição $R$ relaciona $A I M E$ aos benefícios da seguridade. Definindo $A I M E_{t}$ como a média da geração que alcança a idade de 46 no ano $t$ temos:

$$
A I M E_{t}=\sum_{j=1}^{45} \frac{w_{t-46+j, j} e_{j}\left(h_{t-46+j, j}-l_{t-46+j, j}\right)}{45}
$$


onde $w_{t, j}$ e $l_{t, j}$ representam, respectivamente, o salário e o lazer de um indivíduo com a idade $j$ no ano $t$-o primeiro índice representa o ano e o segundo representa a geração. ${ }^{7} \mathrm{O}$ benefício recebido a cada ano até a idade de 55 pela geração que alcançou a idade de 46 no ano $t, B_{t}$, está relacionado à $A I M E_{t}$ por:

$$
B_{t}=R A I M E_{t}
$$

Neste caso, a despesa total anual do sistema de seguridade é dada por:

$$
S_{t}=\sum_{i=0}^{9} N_{t, 46+i} B_{t-i}
$$

A receita anual do sistema de seguridade é dada por:

$$
T_{t}^{S E G}=\tau_{s t} \sum_{j=1}^{45} N_{t, j} w_{t, j} e_{j}\left(h_{t, j}-l_{t, j}\right)
$$

Neste sistema, supomos que os trabalhadores tratam as contribuições para a seguridade social como tributos marginais, onde tributos adicionalmente pagos não geram benefícios adicionais. Além disso, os eventuais déficits do sistema são financiados pelo restante do governo.

\subsection{Equilíbrio de Mercado}

As condições de equilíbrio no mercado de trabalho são dadas por:

$$
L_{t}=\sum_{j=1}^{55} N_{t, j} e_{j}\left(h_{t}-l_{t, j}\right)
$$

O lado esquerdo de (25) representa a demanda agregada por trabalho do setor produtor e o lado direito representa a oferta agregada das famílias. O termo $N_{t, j}$ representa a população de idade $j$ no ano $t$. A riqueza líquida das famílias no ano $t$ é dada por:

$$
A_{t}=\sum_{j=1}^{55} N_{t, j} A_{t, j}
$$

7 Nesta subseção, estamos tratando explicitamente as variáveis com índices que diferem no tempo e na geração, o que não foi feito nas subseções anteriores por motivos de simplificação da notação. 
onde $A_{t, j}$ é a riqueza líquida do indivíduo (família) com $j$ anos de idade no ano $t$. $\mathrm{O}$ equilíbrio no mercado de capitais é dado por:

$$
K_{t}=\sum_{j=1}^{55} N_{t, j} A_{t, j}-D_{t}
$$

Como na equação (25), o lado esquerdo representa a demanda agregada por capital do setor produtivo e o lado direito representa a oferta agregada de capital obtida, deduzindo-se, da riqueza líquida das famílias, o nível de endividamento do governo. O equilíbrio entre oferta e demanda agregadas no mercado de bens é dado por:

$$
C_{t}+I_{t}+G_{t}=Y_{t}
$$

onde:

$$
C_{t}=\sum_{j=1}^{55} N_{t, j} c_{t, j}
$$

$C_{t}$ é a demanda agregada de consumo e $I_{t}$ é a demanda agregada de investimento.

\subsection{Solução do Modelo}

Analisa-se o equilíbrio do modelo sob expectativas racionais. As famílias escolhem as sequências de consumo, lazer e poupança dadas suas expectativas sobre salários, taxas de juros e alíquotas tributárias presentes e futuras. Dadas as suas expectativas, as firmas escolhem, a cada período, os níveis ótimos de capital e trabalho. $\mathrm{O}$ caminho esperado dos impostos deve satisfazer a restrição orçamentária intertemporal. Além disso, os mercados de trabalho e capital devem se equilibrar quando as expectativas ex ante dos preços são iguais às sequências de preços de equilíbrio observadas ex post.

O equilíbrio é dado pelo sistema de equações não lineares formado pelas equações de comportamento das famílias, do setor produtivo e do governo. A solução é obtida pela utilização do método iterativo de Newton-Raphson (ver, por exemplo, DOCQUIER; LIÉGEOIS, 2004). Para obter a solução, supomos que as alterações no regime de política tributária não sejam antecipadas pelas famílias e firmas. 


\section{Calibração do Modelo}

O procedimento de calibração adotado consiste em especificar os valores de todos os parâmetros do modelo (exceto os parâmetros de preferências das famílias) e, em seguida, ajustar os parâmetros da função utilidade, de modo a obter uma solução do modelo próxima do resultado observado da economia em dado ano. As variáveis utilizadas para ajustar a economia são: consumo, poupança, estoque de capital, taxa de juros, arrecadação total, arrecadação da seguridade social, dívida pública e consumo do governo. Uma descrição detalhada da metodologia de calibração deste tipo de modelo pode ser encontrada em Lledo (2005).

A Tabela $Z 1$, a seguir, apresenta os valores de alguns dos principais parâmetros utilizados e os compara com os trabalhos de Lledo (2005) e Ferreira (2004). Os parâmetros tecnológicos foram calculados a partir dos dados observados para a economia brasileira no ano de 2004. A taxa de crescimento da população foi obtida por meio da taxa observada para o ano de 2004. Os demais parâmetros (com exceção dos parâmetros relacionados às preferências) foram obtidos a partir da literatura nacional sobre o tema. Os parâmetros da função utilidade foram ajustados para obter um equilíbrio inicial do modelo próximo do comportamento observado da economia brasileira no ano de 2004, como descrito pelas contas nacionais fornecidas pelo IBGE.

\section{Tabela 1 - Parâmetros Utilizados no Modelo}

\begin{tabular}{clrrr}
\hline Parâmetro & \multicolumn{1}{c}{ Definição } & Modelo & (Lledo,2005) & (Ferreira,2004) \\
\hline$\eta$ & Taxa de crescimento da população & 0,0145 & 0,019 & 0,019 \\
$\rho$ & Elasticidade de substituição intratemporal & 1,15 & 1,15 & 1,10 \\
$\gamma$ & Elasticidade de substituição intertemporal & 0,70 & 0,40 & 0,305 \\
$\alpha$ & Ponderação de preferência por lazer & 0,25 & 0,25 & 0,36 \\
$\delta$ & Taxa de desconto & 0,025 & 0,021 & 0,015 \\
$\mathrm{~A}$ & Parâmetro tecnológico & 1,00 & 1,00 & 0,89 \\
$\theta$ & Participação do capital na renda & 0,30 & 0,50 & 0,50 \\
\hline
\end{tabular}

A Tabela 1 mostra que os valores dos parâmetros utilizados no modelo estão próximos dos valores utilizados em Ferreira (2004) e Lledo (2005), ainda que a elasticidade de substituição intertemporal e a taxa de desconto utilizadas no modelo sejam superiores aos valores utilizados por aqueles autores. As diferenças nesses parâmetros são explicadas, em grande medida, pela introdução, no modelo, de incerteza quanto ao tempo de vida das famílias. 
$\mathrm{Na}$ Tabela 1, pode-se observar que a participação do capital na renda utilizada no modelo é de $30 \%$, enquanto os outros autores utilizam uma participação de 50\%. Esta discrepância é explicada, em parte, pela falta de dados sobre a renda dos autônomos. No cálculo da renda nacional, o IBGE identifica dois grupos de rendimentos: rendimentos exclusivos do trabalho e excedente operacional. Dentro do excedente operacional estão contidos os rendimentos dos autônomos e os demais rendimentos. Os demais rendimentos são rendas exclusivas do capital, mas o rendimento dos autônomos é um rendimento misto, que inclui rendas do capital e rendimentos do trabalho, pois, para este rendimento, o IBGE não possui informação das parcelas referentes ao trabalho e ao capital separadamente. Logo, o valor do parâmetro $\theta$ depende da hipótese sobre a divisão da renda dos autônomos entre capital e trabalho; no presente trabalho, supõe-se que toda a renda dos autônomos pertença ao fator trabalho.

As probabilidades condicionais de sobrevida das famílias foram obtidas das tábuas completas de mortalidade do IBGE para o ano de 2004 e estão expressas no Anexo A. Os valores dos parâmetros restantes estão expressos na Tabela 2 a seguir.

Tabela 2 - Demais Parâmetros do Modelo

\begin{tabular}{lll}
\hline Parâmetro & Definição & Modelo \\
\hline$e_{j}$ & Rendimentos das habilidades & $a=-0,231$ \\
& $e_{j}=\exp \left(a+b j+c f^{2}\right)$ & $b=0,0529$ \\
& & $c=-0,000934$ \\
$\beta_{\mathrm{t}}$ & Parâmetro de dedução tributária do investimento & 0,1 \\
$\psi$ & Parâmetro do custo de ajuste & 0,4 \\
$\phi$ & Taxa de progresso técnico & 0,02 \\
$\tau_{\mathrm{yt}}$ & Alíquota do imposto sobre renda geral & 0,047 \\
$\tau_{\mathrm{st}}$ & Alíquota da contribuição para seguridade & 0,105 \\
$\tau_{\mathrm{tt}}$ & Alíquota do imposto sobre renda do trabalho & 0,06 \\
$\tau_{\mathrm{et}}$ & Alíquota do imposto sobre lucro das empresas & 0,083 \\
\hline
\end{tabular}

O parâmetro $\beta_{t}$ supõe que a legislação permite, em média, uma dedução de $10 \%$ do investimento da base do imposto sobre o lucro das empresas, em função da depreciação esperada. As alíquotas tributárias efetivas foram calculadas a partir dos dados das contas nacionais de 2004 fornecidos pelo IBGE. A alíquota $\tau_{\text {st }}$ corresponde às contribuições previdenciárias. A alíquota $\tau_{e t}$ corresponde ao imposto de renda pessoa jurídica, contribuição social sobre o lucro líquido e impostos indiretos cobrados sobre bens de capital (basicamente PIS e COFINS cobrados sobre bens de capital). A classificação de impostos indiretos cobrados sobre bens de capital como tributos sobre as empresas leva em consideração que esses impostos não oneram o consu- 
mo das famílias, onerando, na realidade, o investimento das empresas. A alíquota $\tau_{1 t}$ é calculada, basicamente, a partir da arrecadação observada da contribuição do salário-educação, contribuições para o sistema S (SESC, SESI, SENAI,etc.) e FGTS. O imposto sobre renda geral, cuja alíquota é $\tau_{y t}$, inclui impostos que incidem sobre o trabalho e o capital, cuja identificação separada exija hipóteses adicionais relativamente arbitrárias. Nessa categoria, estão, basicamente: o imposto de renda pessoa física, o imposto de renda retido na fonte, IPTU, IPVA e CPMF. O imposto sobre o consumo, cuja alíquota é $\tau_{c t}$, inclui os impostos indiretos cobrados sobre os bens de consumo das famílias: ICMS, IPI, PIS, COFINS, etc. A alíquota desse imposto não é um parâmetro do modelo, e sim uma variável endógena que se ajusta para manter a relação dívida/PIB constante. $\mathrm{O}$ procedimento de calibração permite que a alíquota desse imposto e sua arrecadação no modelo sejam muito próximas dos valores observados para as mesmas em 2004.

A Tabela 3, a seguir, descreve o equilíbrio inicial do modelo (estado estacionário) e o ajuste do mesmo em relação ao comportamento observado da economia brasileira em 2004.

Tabela 3 - Ajuste do Modelo em Relação à Economia Brasileira em 2004

\begin{tabular}{lccc}
\hline & $\begin{array}{c}\text { Brasil em 2004 } \\
\text { em \% PIB }\end{array}$ & $\begin{array}{c}\text { Brasil em 2004 } \\
\text { em \% }{ }^{1}\end{array}$ & $\begin{array}{r}\text { Modelo } \\
\text { em \% }^{1}\end{array}$ \\
\hline Consumo & 59,8 & 85,9 & \\
Impostos sobre consumo & 15,9 & 22,8 & \\
Consumo líquido de impostos & 43,9 & 63,1 & 62,1 \\
Poupança bruta & 18,5 & 26,5 & \\
Poupança líquida & 6,5 & 9,3 & 9,9 \\
Capital & & 300,0 & 287,0 \\
Taxa de juros real & 8,0 & 8,0 & 9,6 \\
Arrecadação total & 32,8 & 47,2 & 38,2 \\
Arrecadação líquida & \\
Arrecadação da seguridade & 29,1 & 41,8 & 7,4 \\
Dívida pública & 5,2 & 7,4 & 73,3 \\
Consumo do governo & 49,3 & 70,8 & 28,0 \\
\hline
\end{tabular}

Notas: ${ }^{1} \mathrm{Y}$ é definido como a renda nacional disponível líquida a custo de fatores.

${ }^{2}$ Arrecadação total deduzida da correção monetária sobre a dívida pública.

Observa-se que o modelo está razoavelmente bem calibrado com relação aos dados observados para a economia brasileira em 2004. Cabe ressaltar que o conceito de produto utilizado no modelo é o de renda nacional disponível líquida a custos de fatores, de modo que devem ser comparados os valores observados na terceira coluna 
(Brasil em \% de Y) com os valores do estado estacionário inicial do modelo (quarta coluna); por exemplo, os valores do consumo $(62,1 \%$ de $\mathrm{Y})$ e poupança líquida $(9,9 \%$ de $\mathrm{Y})$, no modelo, estão bem ajustados aos valores observados $(63,1 \%$ de $\mathrm{Y}$ e $9,3 \%$ de $\mathrm{Y}$, respectivamente).

\section{Exercícios de Simulação}

As medidas de desoneração do setor produtivo consideradas nas simulações a seguir classificam-se em duas categorias básicas: medidas que buscam reduzir a tributação sobre o fator trabalho e medidas que visam desonerar principalmente o fator capital. No contexto do modelo teórico apresentado acima, as medidas de desoneração do fator trabalho serão representadas pela redução na alíquota do tributo sobre a renda do trabalho $\left(\tau_{1}\right)$ - "exercício l" -, enquanto que as medidas de desoneração do capital serão representadas pela redução na alíquota do tributo sobre o lucro $\left(\tau_{e}\right)$ - "exercício 2". Também serão apresentados, para fins de comparação, os resultados de um terceiro exercício de simulação, baseado na redução do imposto sobre a renda geral $\left(\tau_{y}\right)$ - que equivale ao caso de redução proporcional nos tributos sobre as rendas do trabalho e do capital. ${ }^{8}$ Em todos os casos, as alíquotas serão reduzidas na magnitude necessária para gerar uma redução da receita tributária em $1 \%$ do PIB; além disso, tais mudanças de política serão compensadas através do aumento da alíquota do imposto sobre o consumo $\left(\tau_{c}\right)$, de tal forma que a redução na arrecadação de uma base tributária seja compensada pelo aumento da arrecadação na outra base, mantendo a dívida pública, como proporção do PIB, constante ao longo do tempo.

Os Gráficos 1, 2 e 3 resumem os principais resultados das simulações. O Gráfico 1 apresenta, para os três exercícios tributários considerados, a variação do estoque de capital na economia ao longo do tempo, relativamente ao nível observado no equilíbrio de steady-state original (antes de qualquer alteração no sistema tributário). Em conformidade com os efeitos teóricos discutidos na seção 2, as três medidas de desoneração da produção levam à maior acumulação de capital em relação ao equilíbrio inicial, sendo que tal efeito é maior no caso da redução do imposto sobre o capital (que gera um novo estoque de capital cerca de $4 \%$ maior do que no equilíbrio inicial) relativamente à redução do imposto sobre o trabalho (que gera um aumento de aproximadamente $1 \%$ ); a redução no imposto sobre a renda geral leva, por motivos óbvios, a um resultado intermediário. É interessante notar que a magnitude da diferença nas trajetórias do estoque de capital sob os exercícios l e

8 Dado que o imposto sobre o trabalho incide sobre uma base tributária significativamente maior do que o imposto sobre o capital, os resultados desse exercício acabam se assemelhando aos resultados do exercício de desoneração apenas do trabalho. 
2 parece bastante expressiva, o que sugere que, para um país com as características da economia brasileira, a desoneração do fator capital pode levar a aumentos substanciais de capital e produto relativamente à desoneração do fator trabalho.

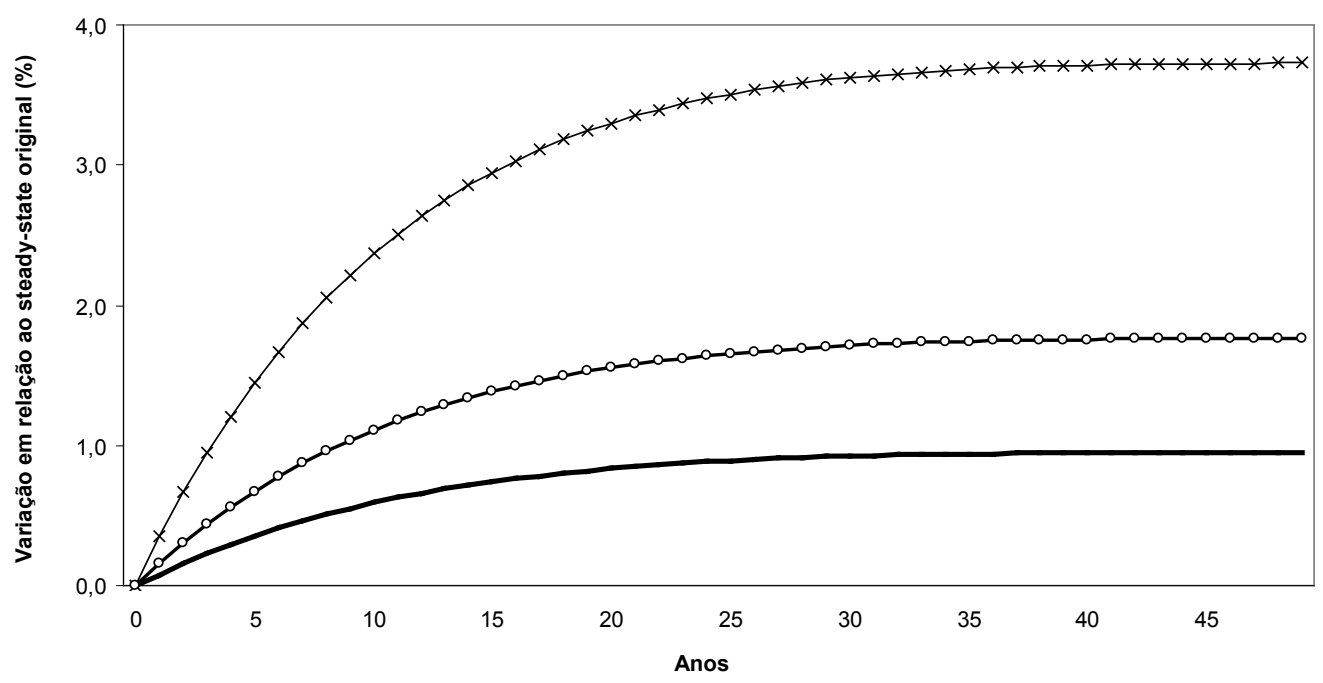

Redução do imposto sobre o trabalho $*$ Redução do imposto sobre o capital $\multimap$ - Redução do imposto sobre a renda

\section{Gráfico 1 - Trajetória do Estoque de Capital Sob Cada Exercício Tributário (Variação em Relação ao Equilíbrio Original, em \%)}

Esta conclusão é confirmada no Gráfico 2, que mostra a variação do PIB sob cada exercício tributário, em relação ao equilíbrio inicial. No caso da redução do imposto sobre o capital, o PIB converge para um novo nível de equilíbrio, $1 \%$ maior do que no equilíbrio inicial, ao passo que a redução do imposto sobre o trabalho gera um ganho de produto de apenas $0,4 \%$ aproximadamente. Tal resultado está, evidentemente, associado ao estoque de capital significativamente maior sob o exercício 1 , relativamente ao exercício 2 . 


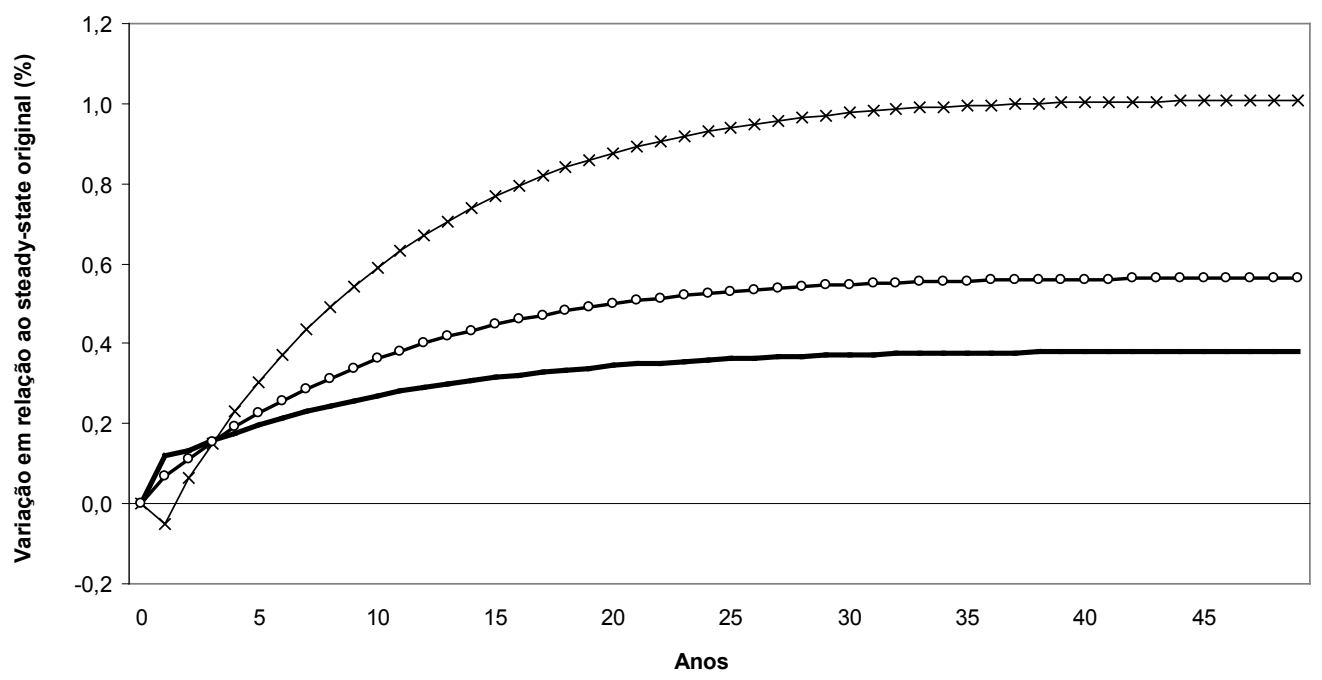

Redução do imposto sobre o trabalho $*$ Redução do imposto sobre o capital $\longrightarrow$-Redução do imposto sobre a renda

\section{Gráfico 2 - Trajetória do PIB Sob Cada Exercício Tributário (Variação em Relação ao Equilíbrio Original, em \%)}

O Gráfico 3 apresenta os impactos das alterações tributárias em questão sobre o bem-estar de cada geração. Essa avaliação é realizada pela mensuração da mudança esperada de bem-estar ao longo da vida de cada geração, definida como o aumento porcentual na dotação de trabalho plena, ao longo da vida restante, ${ }^{9}$ requerida sob o regime tributário inicial, para gerar o mesmo nível de utilidade obtido após a mudança do regime tributário. ${ }^{10}$ Se o acréscimo é positivo para uma geração específica, isso significa que a mesma está em melhor situação após a alteração tributária, pois o nível de utilidade atingido na nova situação é superior ao máximo que a geração atingiria, dada sua riqueza inicial, sob o regime tributário original.

No gráfico, cada geração é identificada pela diferença entre o ano de seu nascimento e o ano em que a alteração tributária foi realizada. Assim, por exemplo, a geração 36 corresponde aos indivíduos que nasceram 36 anos antes da alteração, enquanto que a geração 9 corresponde aos indivíduos nascidos nove anos após a alteração tributária.

9 No momento em que a alteração tributária é realizada.

10 Esta medida é um tipo de medida de variação equivalente do bem-estar. Ela compara dois pontos na função utilidade indireta com métrica monetária. Esta função é definida como a função gasto do problema do consumidor descrito no modelo. Neste caso, a função gasto depende dos preços e da função utilidade indireta (obtida a partir da função utilidade direta descrita no modelo). A variação equivalente é um tipo mais geral de medida de alteração do bem-estar e geralmente é diferente do excedente do consumidor. Eles somente são iguais quando a função utilidade é quase linear. Para maiores detalhes, vide Varian (1992). 


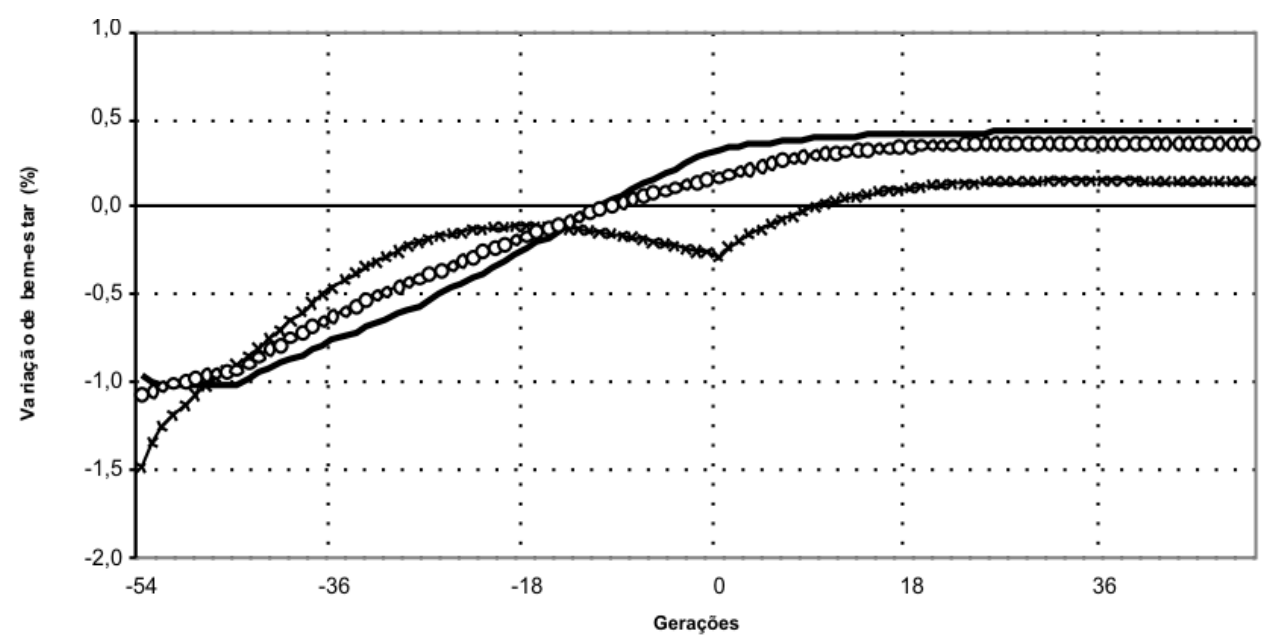

- Redução do imposto sobre o trabalho $\rightarrow$ - Redução do imposto sobre o capital $\rightarrow$ - Redução do imposto sobre a renda

\section{Gráfico 3 - Níveis de Bem-Estar Sob Cada Exercício Tributário, por Geração (Variação em Relação ao Equilíbrio Original, em \%)}

De acordo com o gráfico, os três exercícios tributários apresentam em comum o fato de que as gerações mais velhas, existentes no momento da alteração tributária, sofrem perda de bem-estar em função dessa alteração, ao passo que todas as gerações, nascidas pelo menos 10 anos após a reforma, obtém ganhos de bem-estar. Contudo, apesar desse resultado em comum, os exercícios considerados apresentam diferenças no que se refere às magnitudes dos ganhos e perdas dessas gerações "extremas", bem como padrões de distribuição intergeracional de ganhos e perdas bastante distintos no que se refere às gerações "intermediárias”. Em particular, observa-se que:

i) A redução do imposto sobre o trabalho (e, em menor grau, sobre a renda geral) gera ganhos de bem-estar significativamente maiores para as gerações futuras, relativamente à redução do tributo sobre o capital.

ii) No caso da desoneração do fator trabalho (e também sobre a renda geral), a variação de bem-estar entre gerações é quase monotônica, sendo que todas as gerações com menos de 11 anos, no momento da alteração tributária, auferem ganhos de bem-estar, enquanto que as gerações mais velhas sofrem perdas.

iii) No caso da desoneração do capital, apenas as gerações nascidas 10 anos ou mais após a alteração tributária obtêm ganhos de bem-estar, enquanto que todas as gerações nascidas antes disso perdem bem-estar. É interessante observar, porém, que as perdas de bem-estar, para essas gerações, não variam de forma monotônica 
com a idade; em especial, as perdas de bem-estar, para as gerações nascidas entre aproximadamente 25 e 10 anos antes da alteração tributária, são menores do que as perdas observadas para as gerações nascidas antes disso, ou mais próximo do momento da reforma.

O resultado (i) acima pode ser explicado pelo fato de que, apesar dos maiores níveis de capital e produto no longo prazo, o regime de desoneração do capital se caracteriza por taxação elevada de ambos: o consumo e o trabalho, levando a menores níveis de utilidade das gerações futuras. ${ }^{11}$ Por sua vez, a diferença entre os resultados (ii) e (iii) está associada fundamentalmente à flexibilidade de cada geração para reagir e adaptar-se a cada um dos novos regimes tributários. No caso da redução do imposto sobre o trabalho (e aumento do imposto sobre o consumo), a regra é relativamente simples: as gerações que ainda trabalham tendem a trabalhar mais. Quanto mais tempo de vida restante houver, maior será a capacidade dessas gerações desfrutarem do maior produto gerado pelo aumento da taxa de poupança, o que tende a compensá-las parcialmente pelo aumento do preço efetivo do consumo; surge, assim, uma relação monótona decrescente entre idade e variação de bem-estar. No caso da redução do imposto sobre o capital (e aumento do imposto sobre o consumo), há dois efeitos operando: de um lado, o barateamento relativo do capital leva a maior produção e maior consumo futuro, beneficiando as gerações mais novas (que poderão usufruir desse maior produto); de outro lado, algumas gerações intermediárias, que já conseguiram acumular certos níveis de capital, são beneficiadas pela redução na tributação da renda advinda desse fator, o que compensa parcialmente o fato de suas vidas restantes não serem tão longas. O resultado líquido é a curva em formato de "u" invertido do gráfico.

\section{Conclusão}

Neste trabalho, buscou-se contribuir para o debate sobre a forma ideal de desoneração do setor produtivo, através da simulação de diferentes medidas de reforma tributária no País a partir de um modelo de equilíbrio geral com gerações superpostas, calibrado para o Brasil. Buscou-se, em particular, comparar medidas de desoneração do fator trabalho e medidas de desoneração do fator capital, ambas compensadas por aumentos na tributação do consumo, no que tange a seus impactos esperados sobre o PIB, acumulação de capital e nível de bem-estar no País.

De acordo com os resultados obtidos, a desoneração do fator capital pode levar a aumentos substanciais de capital e produto relativamente à desoneração do fator

11 Vale notar que esse resultado se mantém basicamente alterado quando se adotam os valores dos parâmetros da função utilidade utilizados nos trabalhos de Lledo (2005) e Ferreira (2004). 
trabalho. Ambas as políticas devem gerar perdas de bem-estar para as gerações mais velhas existentes no momento da reforma tributária e ganhos de bem-estar para as gerações futuras, mas os efeitos sobre as gerações intermediárias podem ser bastante distintos em cada caso.

Vale ressaltar algumas das principais limitações do modelo usado neste estudo como instrumento de avaliação de reformas tributárias. Primeiro, a hipótese de concorrência perfeita pode não ser a mais adequada, caso a economia inclua muitos setores produtivos com poder de mercado para a fixação de preços; a consideração explícita da existência de poder de mercado poderia alterar a sensibilidade das decisões de produção a variações tributárias, gerando efeitos agregados diferentes daqueles encontrados no estudo. Segundo, o modelo não considera a possibilidade de diferenças entre os indivíduos de uma mesma geração - ignorando, por exemplo, a possibilidade de que famílias pobres pertencentes a certa geração possam ter comportamento diferente de famílias ricas da mesma geração. Uma análise mais rica, que incluísse diferenças intrageracionais, poderia levar a resultados distintos no que se refere à evolução esperada dos agregados macroeconômicos e, principalmente, à análise de bem-estar. Terceiro, a hipótese de ausência de heranças voluntárias restringe a flexibilidade dos aposentados para reagirem a mudanças na tributação sobre o consumo. Quarto, a adoção de uma função de produção neoclássica, que ignora a possibilidade de crescimento endógeno, pode subestimar a magnitude dos impactos macroeconômicos de alterações tributárias. Pretende-se, em trabalhos futuros, avançar na análise de reformas tributárias através do uso de um modelo teórico que incorpore um ou mais desses aspectos.

\section{Referências}

AFONSO, José R. R.; VARSANO, Ricardo. Reforma tributária: sonhos e frustrações. In: GIAMBIAGI, Reis; URANI, André. (Org.). Reforma no Brasil: balanço e agenda. Rio de Janeiro: Nova Fronteira, 2004.

AUERBACH, Alan J.; KOTLIKOFF, Laurence J. Dynamic fiscal policy. Cambridge: Cambridge University Press, 1987.

BARRETO, Flávio. Três ensaios sobre reforma de sistemas previdenciários. Tese (Doutorado em Economia) - Fundação Getúlio Vargas, Rio de Janeiro, 1997.

BARRETO, Flávio; OLIVEIRA, Luiz G. S. Aplicação de um modelo de gerações superpostas para a reforma da previdência no Brasil: uma análise de sensibilidade no estado estacionário. Anais do XVII Encontro Brasileiro de Econometria, Salvador-BA, SBE, 1995.

. Transição para regimes previdenciários de capitalização e seus efeitos macroeconômicos de longo prazo no Brasil. Estudos Econômicos, v. 31, n. 1, 2001. 
DOCQUIER, Frédéric; LIÉGEOIS, Philippe, Simulating computable overlapping generations models with TROLL. Computational Economics, v. 23, p. 1-19, 2004.

ELLERY JUNIOR, Roberto de G.; BUGARIN, Mirta N. S. Previdência social e bem estar no Brasil. Revista Brasileira de Economia, v. 57, n. 1, 2003.

FERREIRA, Pedro C. G.; ARAÚJO, Carlos H. V. Reforma tributária efeitos alocativos e impactos de bem-estar. Revista Brasileira de Economia, v. 53, n. 2, 1999.

FERREIRA, Pedro C. G.; NASCIMENTO, Leandro G. do. Welfare and growth effects of alternative fiscal rules for infrastructure investment in Brazil. Ensaios Econômicos EPGE, nov. 2005.

FERREIRA, Sérgio G. Social security reforms under an open economy: the Brazilian case. Revista Brasileira de Economia, v. 58, n. 3, 2004.

FOCHEZATTO, Adelar; SALAMI, Carlos R. Avaliando os impactos de políticas tributárias sobre a economia brasileira com base em um modelo de equilíbrio geral de gerações superpostas. Revista Brasileira de Economia, v. 63, n.3, 2009.

JOKISCH, Sabini; KOTLIKOFF, Laurence J. Simulating the dynamic macroeconomic effects of the fairtax. The National Tax Journal, 2007.

LANNES JR., Osmar P. Aspectos macroeconômicos da reforma da previdência social no Brasil: duas análises em equilíbrio geral com restrições ao crédito. Tese (Doutorado em Economia) - Fundação Getúlio Vargas, Rio de Janeiro, 1999.

LANNES JR., Osmar P.; OLIVEIRA, Luiz G. S. Avaliação dos efeitos de bem-estar associados à mudança do regime previdenciário: uma análise de equilíbrio geral computável na presença de restrições ao crédito. Anais do XX Encontro Brasileiro de Econometria, Vitória-ES, SBE, 1998.

LLEDO, Victor D. Tax systems under fiscal adjustment: a dynamic CGE analysis of the Brazilian tax reform. IMF Working Paper, July 2005.

MENEZES, Francisco M.S.; BARRETO, Flávio A. Reforma tributária no Brasil: lições de um modelo de equilíbrio geral aplicado. Revista Econômica do Nordeste, Fortaleza, v. 30, n. especial, p. 524-535, dez. 1999.

SILVA, Napoleão L. C. da; TOURINHO, Octávio A. F.; ALVES, Yann L. B. O impacto da reforma tributária na economia brasileira: uma análise com o modelo CGE. In: Texto para Discussão $n^{\circ}$ 1056, IPEA, Rio de Janeiro, nov. 2004.

TELES, Vladimir K.; ANDRADE, Joaquim P. Reformas tributária e previdenciária e a economia brasileira no longo prazo. Revista Brasileira de Economia, v. 60, n. 1, p. 87-107, 2006.

VARIAN, Hal R. Microeconomic analysis, New York: W. W. Norton, 1992.

VIGNA, Bruno Z. A previdência social brasileira após a transição demográfica: simulações de propostas de reforma. Anais do XXXIV Encontro Nacional de Economia, Salvador-BA, ANPEC, 2006. 


\section{ANEXO A}

\section{Tabela A1}

\begin{tabular}{|c|c|c|c|}
\hline $\begin{array}{c}\text { Idades } \\
\text { Exatas } \\
(X) \\
\end{array}$ & $\begin{array}{l}\text { Probabilidades de Morte } \\
\text { entre Duas Idades Exatas } \\
Q(X, N) \text { (Por Mil) }\end{array}$ & $\begin{array}{c}\text { Idades } \\
\text { Exatas } \\
(X) \\
\end{array}$ & $\begin{array}{c}\text { Probabilidades de Morte } \\
\text { entre Duas Idades Exatas } \\
Q(X, N) \text { (Por Mil) }\end{array}$ \\
\hline 21 & 1,727 & 49 & 6,630 \\
\hline 22 & 1,835 & 50 & 7,040 \\
\hline 23 & 1,899 & 51 & 7,495 \\
\hline 24 & 1,954 & 52 & 8,018 \\
\hline 25 & 2,015 & 53 & 8,624 \\
\hline 26 & 2,050 & 54 & 9,304 \\
\hline 27 & 2,093 & 55 & 10,044 \\
\hline 28 & 2,153 & 56 & 10,825 \\
\hline 29 & 2,226 & 57 & 11,643 \\
\hline 30 & 2,307 & 58 & 12,494 \\
\hline 31 & 2,389 & 59 & 13,388 \\
\hline 32 & 2,479 & 60 & 14,348 \\
\hline 33 & 2,575 & 61 & 15,390 \\
\hline 34 & 2,681 & 62 & 16,514 \\
\hline 35 & 2,797 & 63 & 17,732 \\
\hline 36 & 2,930 & 64 & 19,053 \\
\hline 37 & 3,084 & 65 & 20,455 \\
\hline 38 & 3,263 & 66 & 21,975 \\
\hline 39 & 3,465 & 67 & 23,691 \\
\hline 40 & 3,686 & 68 & 25,650 \\
\hline 41 & 3,925 & 69 & 27,839 \\
\hline 42 & 4,188 & 70 & 30,200 \\
\hline 43 & 4,477 & 71 & 32,713 \\
\hline 44 & 4,790 & 72 & 35,424 \\
\hline 45 & 5,135 & 73 & 38,347 \\
\hline 46 & 5,502 & 74 & 41,496 \\
\hline 47 & 5,876 & 75 & 44,875 \\
\hline 48 & 6,241 & & \\
\hline
\end{tabular}

Fonte: IBGE - COPIS.

Notas: $N=1 ; Q(X, N)=$ Probabilidades de morte entre as idades exatas $X$ e $X+N$. 